American Journal of Applied Sciences 7 (1): 110-119, 2010

ISSN 1546-9239

(C) 2010 Science Publications

\title{
Using an Adaptative Fuzzy-Logic System to Optimize the Performances and the Reduction of Chattering Phenomenon in the Control of Induction Motor
}

\author{
${ }^{1}$ M.M. Krishan, ${ }^{2}$ L. Barazane and ${ }^{3}$ A. Khwaldeh \\ ${ }^{1}$ Department of Electromechanical Engineering, Al-Balq'a Applied University, \\ Engineering of Information and Measurement Systems, P.O. Box 13116 Zarka, Jordan \\ ${ }^{2}$ Department of Electrical Engineering, Faculty of Electronic and Computing, \\ University of Science and Technology Houari, Boumediene, P.O. Box 32, El-Alia, \\ Bab-Ezzouar 16111, Algiers, Algeria \\ ${ }^{3}$ Department of Computer Sciences Engineering, Faculty of Engineering, \\ P.O. Box 1 Philadelphia University, 19392, Jordan
}

\begin{abstract}
Problem statement: Neural networks and fuzzy inference systems are becoming wellrecognized tools of designing an identifier/controller capable of perceiving the operating environment and imitating a human operator with high performance. Also, by combining these two features, more versatile and robust models, called "neuro-fuzzy" architectures have been developed. The mo Approach: Motivation behind the use of neuro-fuzzy approaches was based on the complexity of real life systems, ambiguities on sensory information or time-varying nature of the system under investigation. In this way, the present contribution concerns the application of neuro-fuzzy approach in order to perform the responses of the speed regulation, ensure more robustness of the overall system and to reduce the chattering phenomenon introduced by sliding mode control which is very harmful to the actuators in our case and may excite the unmodeled dynamics of the system. Results: In fact, the aim of such a research consists first in simplifying the control of the motor by decoupling between two principles variables which provoque the torque in the motor by using the feedback linearization method. Then, using sliding mode controllers to give our process more robustness towards the variation of different parameters of the motor. However, the latter technique of control called sliding mode control caused an indesirable phenomenon which harmful and could leads to the deterioration of the inverter's components called "chattering". So, here the authors propose to use neuro-fuzzy systems to reduce this phenomenon and perform the performances of the adopted control process. The type of the neuro-fuzzy system used here is called": Adaptive Neuro Fuzzy Inference System (ANFIS)". This neuro-fuzzy is destined to replace the speed fuzzy sliding mode controller after its training process. Conclusion: Therefore, from a control design consideration, the adopted neuro-fuzzy system has opened up a new direction that allows for the design of robust controllers for uncertain non-linear dynamical systems without resorting to system model simplifications and linearization and without imposing structural conditions on system uncertainties. On the other hand, it is important to say that this approach permits to improve the performance of the controlled system only by choosing the appropriate form of the membership functions (shape, triangular...) and a good partionnement of the universe of discourse of the diverse variables. Finally the obtained simulation results prove that the objectives of the authors where attempt by a significant reduction of the chattering and a good robustness of the process towards parameter variation and external perturbation (load torque).
\end{abstract}

Key words: Nonlinear feedback control, sliding mode control, Adaptive Neuro Fuzzy Inference System, ANFIS, induction motor

\section{INTRODUCTION}

Twentieth century has witnessed widespread innovations in both hardware and software design. In fact, the development of fast microprocessors enabled the design and implementation of expert-machine interaction based computation environments. Ever increasing needs brought about by the multi-

Corresponding Author: M.M. Krishan, Department of Electromechanical Engineering, Al-Balq'a Applied University, Engineering of Information and Measurement Systems, P.O. Box 13116 Zarka, Jordan 
dimensionality of the problem space and time-varying behavior of real-life physical systems further required to reduce the role of expert and to increase the role of the machine. A natural consequence of this rapid growth is the emergence of the field of intelligent systems, or in other words, the field of neuro-fuzzy systems (Efe and Kaynak, 1999; Jang et al., 1997).

Neural networks and fuzzy controllers are both capable of controlling nonlinear dynamical systems. However, the disadvantage of neural control is that it is not obvious how the network solves the respective control task. It is not possible in general to retrieve any kind of structural knowledge from network that could be formulated in some kind of rules, or to use prior knowledge to reduce the learning time. The network has to learn from scratch and might have to do so again if substantial parameters of the dynamical system change for some reason (Efe and Kaynak, 1999; Hunt and Sbarbaro, 1991; Kosko, 1992; Narendra and Parthasarathy, 1990; Isidori, 1999).

On the other hand, the use of fuzzy controllers consists on the interpretation of the behavior based on the explicit linguistic rules the controller consist of. Fuzzy inference systems or controllers describe systems by establishing relations between the relevant variables in the form of "If-Then" rules that are to a certain degree transparent to interpretation and analysis. Nevertheless, the design problems of a fuzzy controller are the choice of appropriate fuzzy if-then-rules, the membership functions and the tuning of both in order to improve the performance of the fuzzy controller (Ghalia and Alouani, 1995; Li et al., 1997; Utkin, 1992). So, in order to overcome these problems the combination of the two techniques was proposed by different researchers to give another type of intelligent systems called "neuro-fuzzy systems". The design of such controllers combine architectural (by neural network) and philosophical (by fuzzy systems) aspects of an expert resulting in an artificial brain, which could be used as controllers or identifiers. The most questionable quality in the use of neuro-fuzzy systems to control different process is the robustness towards parameters variation of the process and external perturbations...., (Efe and Kaynak, 1999; Jang et al., 1997). One of such intelligent systems is the Adaptive Neuro-Fuzzy Inference System (ANFIS) which is a fuzzy inference system implemented within the architecture and learning procedure of adaptive networks which is a superset of all kinds of feedforward neural networks with supervised learning capability (Jang et al., 1997). There are various successful examples of ANFIS used in different applications such as: robotic, imaging treatment and also in electrical motor drives especially in the induction motor drives which is the aim of this study. In fact, they are able to give a process many advantages such as: The optimization of the performance of the control of motor drives, ensuring the robustness towards parameter variations and external disturbances and also, reducing the chattering phenomenon when the control of the motor is based initially on the variable structure control (Barazane et al., 2009). In fact, the principal aim of the present work consists in the conception of an adaptive neuro-fuzzy sliding mode controller which is used to copy the comportment of the speed sliding mode controller in order to permit an improvement of the performance of the system and to reduce considerably the chattering phenomenon which is very harmful to the actuators in our case and may excite the unmodeled dynamics of the system. The designation of neuro-fuzzy sliding mode controller is given from the fact that the training process of the adopted neural network is done on basis of the input/output pattern collected during the functioning of the system with the speed sliding mode controller. Finally, Simulation results reveal some very interesting features.

This study is organized as follows: In the first segment, the architecture of the Adaptive Neuro-Fuzzy Inference System (ANFIS) and all the corresponding concepts are detailed, followed by the presentation of the feedback linearization control applied to the induction motor. After more, the concepts of sliding mode control are given with the proposition of a new discontinuous control law and then applied in the next segment to conceive the controllers of our previous control scheme. In this segment, the different steps of the conception of these latter's are detailed and their adoption in this work is then validated by simulation. However, such a sliding mode control scheme is characterized by an important disadvantage which is the chattering phenomenon cited previously, that must be reduced. So, therefore, in the following segment and in order to reduce significantly such a phenomenon, adaptive neural network is conceived and trained in order to copy the comportment of the adopted speed sliding mode controller leading to more improvement of the performance of the obtained control scheme and permits to attempt the required objective. Finally, the research concludes with comparison between the different simulation results obtained in all the control methods which are used in the present research.

Architecture of the Adaptive Neuro-Fuzzy Inference System (ANFIS): Combining both fuzzy logic and 
artificial neural networks allows achieving all of the advantages of both systems. Human expert knowledge can be used to build the initial structure of the regulator. On-line or off-line learning processes can improve underdone parts of the structure.

The ANFIS structure is one of the proposed methods to combine fuzzy logic and artificial neural networks. This inference system is the same as a conventional fuzzy structure shown in Fig. 1. It contains rule base and database (knowledge base), fuzzyfication and defuzzyfication unit as well as a decision-making unit (Jang, 1993; Jang et al., 1997). The structure proposed in (Jang, 1993) five network layers. Note that, two inputs are used (xy) and one output (f) (which is a limitation of Sugeno-type systems, i.e., that there is only a single output, obtained using weighted average defuzzification (linear or constant output membership functions) (Jang et al., 1997).

In the first layer, all nodes are adaptive and every one contains membership functions which usually choose as a triangular or bell-shaped function. Here, $i$ is the degree of the membership of the input to the fuzzy Membership Function (MF) represented by node:

$\mathrm{O}_{\mathrm{li}}=\mu_{\mathrm{Ai}}(\mathrm{x}) ; \mathrm{i}=1,2$

$\mathrm{O}_{\mathrm{li}}=\mu_{\mathrm{Bi}-2}(\mathrm{y}) ; \mathrm{i}=3,4$

where, $\mathrm{O}_{\mathrm{li}}$ is the output of the node $\mathrm{i}$ in a layer 1 .

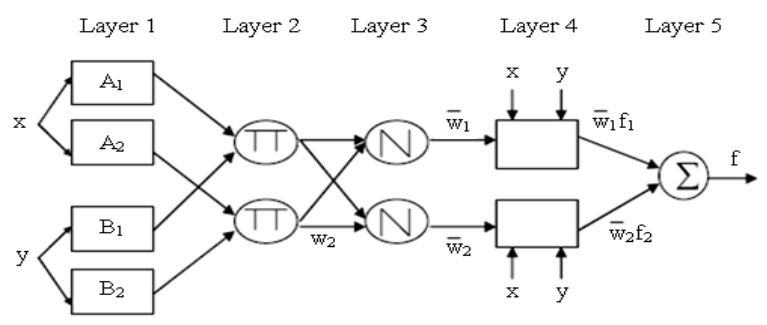

Fig. 1: A five-layer ANFIS structure

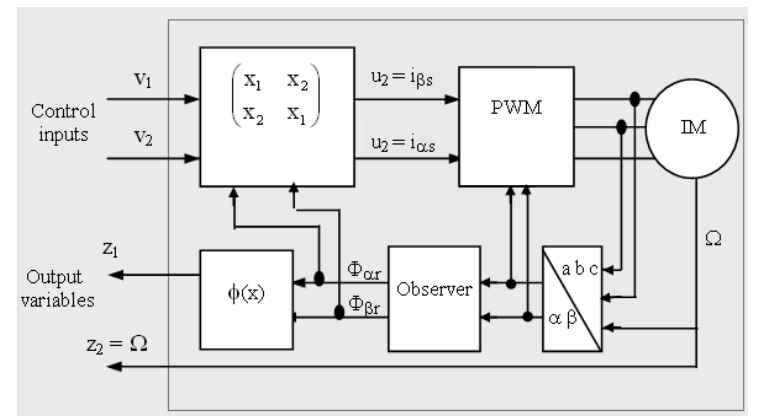

Fig. 2: Block diagram of the nonlinear feedback based control system
In the second layer the nodes are fixed (i.e., that they are not adaptive) and must choose the minimum value of two input weights. In Fig. 2, nodes in this layer are labeled " $\Pi$ " and they are multiply the signal before outputting as follows:

$\left.\mathrm{O}_{2 \mathrm{i}}=\mathrm{w}_{1}=\mu_{\mathrm{A}}(\mathrm{x}) \cdot \mu_{\mathrm{Bi}} \mathrm{y}\right) ; \mathrm{i}=1 ; 2$

Each node output in this layer represents the firing strength of the rule.

In the third layer, every node is also fixed and are labeled with an $\mathrm{N}$ and perform a normalization of the firing strength from the previous layer. The output of each node is given by:

$$
\mathrm{O}_{3 \mathrm{i}}=\overline{\mathrm{w}}=\frac{\mathrm{w}_{\mathrm{i}}}{\mathrm{w}_{1}+\mathrm{w}_{2}} ; \mathrm{i}=1,2
$$

In the fourth layer, all nodes are adaptive. The output of a node is the product of the normalized firing strength and a first order polynomial and is given by:

$\mathrm{O}_{4 \mathrm{i}}=\overline{\mathrm{w}} \cdot \mathrm{f}_{\mathrm{i} 2}=\overline{\mathrm{w}}_{\mathrm{i}}(\mathrm{p} \cdot \mathrm{x}+\mathrm{q} \cdot \mathrm{y}+\mathrm{r}) ; \quad \mathrm{i}=1,2$

where, $\left\{\mathrm{p}_{1} \mathrm{x}, \mathrm{q}_{1} . \mathrm{y}, \mathrm{r}_{1}\right\}$ is the modifiable parameter set, referred to as consequent parameters since they deal with the then part of the fuzzy rule.

Finally, layer 5 is a single node labeled with " $\Sigma$ " which indicates that the function is that of computing the overall output as the summation of all incoming signals defined as:

$\mathrm{O}_{5 \mathrm{i}}=\mathrm{f}=\sum \overline{\mathrm{w}}_{\mathrm{i}} \cdot \mathrm{f}_{\mathrm{i}}=\frac{\sum_{\mathrm{i}} \mathrm{w}_{\mathrm{i}} \cdot \mathrm{f}_{\mathrm{i}}}{\sum_{\mathrm{i}} \mathrm{w}_{\mathrm{i}}} ; \quad \mathrm{i}=1,2$

The ANFIS structure has been tuned automatically by a least-square estimation (for output membership functions) and a back propagation (for output and input membership functions) algorithms. Because its flexibility its is well known that ANFIS system could be used in wide range of control tasks (Jang, 1993; Jang et al., 1997). Further details of the ANFIS model can be obtained from Jang (Jang, 1993; Jang et al., 1997).

Nonlinear feedback control: The state equations of the voltage PWM source inverter fed induction motor with current control, in a stator reference frame $(\alpha-\beta)$, with $\left(\mathfrak{l}_{\alpha \mathrm{s}}, \mathfrak{l}_{\beta \mathrm{s}}\right)$ as command variables and $\left(\phi_{\alpha \mathrm{r}}, \phi_{\beta \mathrm{r}}, \Omega\right)$ as state variables are given (Barazane et al., 2004; 2007; 2009):

$$
\dot{\mathrm{x}}=\mathrm{f}(\mathrm{x})+\mathrm{g}(\mathrm{x}) \cdot \mathrm{u}
$$


Am. J. Applied Sci., 7 (1): 110-119, 2010

Where:

$$
\begin{aligned}
& \mathrm{x}=\left(\mathrm{x}_{1}, \mathrm{x}_{2}, \mathrm{x}_{3}\right)^{\mathrm{t}}=\left(\Phi_{\alpha \mathrm{r}}, \Phi_{\beta \mathrm{r}}, \Omega\right)^{\mathrm{t}} \\
& \mathrm{u}=\left(\mathrm{u}_{1}, \mathrm{u}_{2}\right)^{\mathrm{t}}=\left(\mathrm{i}_{\alpha \mathrm{s}}, \mathrm{i}_{\beta \mathrm{s}}\right)^{t}
\end{aligned}
$$$$
f(x)=\left[\begin{array}{l}
f_{1}(x) \\
f_{2}(x) \\
f_{3}(x)
\end{array}\right]=\left[\begin{array}{l}
\frac{-x_{1}}{T_{r}} p \cdot x_{2} \cdot x_{3} \\
\frac{-x_{2}}{T_{r}} p \cdot x_{1} \cdot x_{3} \\
-\frac{T_{L}}{J}
\end{array}\right]
$$$$
g(x)=\left[\begin{array}{ll}
g_{1}(x) & g_{2}(x)
\end{array}\right]=\left[\begin{array}{cc}
\frac{L_{m}}{T_{r}} & 0 \\
0 & \frac{L_{m}}{T_{r}} \\
\frac{-p L_{m}}{J_{\mathrm{r}}} x_{2} & \frac{\mathrm{pL}_{m}}{J L_{r}} x_{1}
\end{array}\right]
$$

In order to linearize the system (7), two variables which dependent on $\mathrm{x}$ only, are considered as outputs of the system. They are defined as:

$$
\begin{aligned}
& \phi_{1}(\mathrm{x})=\mathrm{z}_{1}=\mathrm{x}_{1}{ }^{2}+\mathrm{x}_{2}{ }^{2}=\Phi_{\alpha \mathrm{r}}{ }^{2}+\Phi_{\beta \mathrm{r}}{ }^{2}=\Phi_{\mathrm{r}}{ }^{2} \\
& \phi_{2}()=\mathrm{z}_{2}=\mathrm{x}_{3}=\Omega
\end{aligned}
$$

The relative degree $r_{i}(i=1,2)$ for each output $\left(z_{1}\right.$, $z_{2}$ ), is in this case are equals to $r_{1}=1$ and $r_{2}=1$ respectively.

This implies that the full-linearization is not realized, so, another variable $\phi_{3}(\mathrm{x})$, which represents the internal dynamic must be added.

Let $\phi_{3}(\mathrm{x})$ be chosen as:

$$
\phi_{3}(\mathrm{x})=\mathrm{z}_{3}=\mathrm{a} \tan \left(\mathrm{x}_{2} / \mathrm{x}_{1}\right)+\mathrm{k} \pi \text { with } \mathrm{k}=\left\{\begin{array}{lll}
0 & \text { if } & \mathrm{x}_{1}>0 \\
1 & \text { if } & \mathrm{x}_{1}<0
\end{array}\right.
$$

Notice that the transformation $\phi(\mathrm{x})$ is reversible.

Consequently, the above set of new coordinates, allows the following canonical form of the system:

$$
\begin{aligned}
& \left(\begin{array}{l}
\dot{\mathrm{z}}_{1} \\
\dot{\mathrm{z}}_{2}
\end{array}\right)=\left(\begin{array}{l}
-\frac{2}{\mathrm{~T}_{\mathrm{r}}} \mathrm{z}_{1} \\
\frac{\mathrm{T}_{\mathrm{L}}}{\mathrm{J}}
\end{array}\right)+\left(\begin{array}{cc}
2 \frac{\mathrm{L}_{\mathrm{m}}}{\mathrm{T}_{\mathrm{r}}} \mathrm{x}_{1} & 2 \frac{\mathrm{L}_{\mathrm{m}}}{\mathrm{T}_{\mathrm{r}}} \mathrm{x}_{2} \\
-\frac{\mathrm{pL} \mathrm{L}_{\mathrm{m}}}{\mathrm{JL}} \mathrm{x}_{2} & \frac{\mathrm{pL}_{\mathrm{m}}}{\mathrm{JL}_{\mathrm{r}}} \mathrm{x}_{1}
\end{array}\right) \cdot\left(\begin{array}{l}
\mathrm{u}_{1} \\
\mathrm{u}_{2}
\end{array}\right) \\
& \dot{\mathrm{z}}_{3}=p \cdot \mathrm{z}_{2}+\frac{\mathrm{L}_{\mathrm{m}}}{\mathrm{T}_{\mathrm{r}}}\left(\frac{\mathrm{x}_{1} \mathrm{u}_{2}-\mathrm{x}_{2} \mathrm{u}_{1}}{\mathrm{x}_{2}}\right)
\end{aligned}
$$

The system (12a) can be presented in the following matrix form:

$$
\dot{\mathrm{z}}_{\mathrm{r}}=\mathrm{A}(\mathrm{z})+\mathrm{B}(\mathrm{z}) \cdot \mathrm{u}
$$

Where:

$$
\begin{aligned}
\dot{\mathrm{z}}_{\mathrm{r}} & =\left(\mathrm{z}_{1}, \mathrm{z}_{2}\right)^{\mathrm{t}} \\
\mathrm{u} & =\left(\mathrm{u}_{1}, \mathrm{u}_{2}\right)^{\mathrm{t}} \\
\mathrm{z} & =\left(\mathrm{z}_{1}, \mathrm{z}_{2}, \mathrm{z}_{3}\right)^{\mathrm{t}} \\
\mathrm{B}(\mathrm{z}) & =\text { Representing the decoupling matrix }
\end{aligned}
$$

In order to realize the feedback control, it is necessary to have the decoupling matrix reversible, which means that its determinant cannot be zero (Slotine and Li, 1991).

Then:

$\operatorname{det}(\mathrm{B}(\mathrm{z}))=\frac{2 \mathrm{~L}_{\mathrm{m}}}{\mathrm{T}_{\mathrm{r}}} \cdot \frac{\mathrm{pL}_{\mathrm{m}}}{\mathrm{JL}_{\mathrm{r}}} \cdot \mathrm{z}_{1} \neq 0$

Accordingly, linearizing feedback is defined as follows:

$\mathrm{u}=\mathrm{B}^{-1}(\mathrm{z})\left(\dot{\mathrm{z}}_{\mathrm{r}}-\mathrm{A}(\mathrm{z})\right)$

which can be explicitly written as:

$$
\left(\begin{array}{l}
\mathrm{u}_{1} \\
\mathrm{u}_{2}
\end{array}\right)=\frac{1}{\operatorname{det}(\mathrm{B}(\mathrm{z}))}+\left(\begin{array}{ll}
\frac{\mathrm{pL}_{\mathrm{m}}}{\mathrm{JL}_{\mathrm{r}}} \mathrm{x}_{1} & \frac{2 \mathrm{~L}_{\mathrm{m}}}{\mathrm{T}_{\mathrm{r}}} \mathrm{x}_{2} \\
\frac{\mathrm{pL} \mathrm{L}_{\mathrm{m}}}{\mathrm{JL}_{\mathrm{r}}} \mathrm{x}_{2} & \frac{2 \mathrm{~L}_{\mathrm{m}}}{\mathrm{T}_{\mathrm{r}}} \mathrm{x}_{1}
\end{array}\right) \cdot\left(\begin{array}{c}
\dot{\mathrm{z}}_{1}+\frac{2}{\mathrm{~T}_{\mathrm{r}}} \mathrm{z}_{1} \\
\dot{\mathrm{z}}_{2}+\frac{\mathrm{T}_{\mathrm{L}}}{\mathrm{J}}
\end{array}\right)
$$

However, we notice in this case that system (16) is rather complex and depends closely on motor parameters, state variables and external perturbations.

In order to minimize the number of input variables and reduce the dependence of the system (16) on parameter variations and external perturbations, while maintaining decoupling between the two subsystems ordered by the command variables $\mathrm{v}_{1}$ and $\mathrm{v}_{2}$, we propose a new reformulation of the system.

By considering $\mathrm{v}_{1}$ and $\mathrm{v}_{2}$ as the new commands variables, $\mathrm{u}_{1}$ and $\mathrm{u}_{2}$ are given as follows:

$\left(\begin{array}{l}u_{1} \\ u_{2}\end{array}\right)=\left(\begin{array}{cc}x_{1} & -x_{2} \\ x_{2} & x_{1}\end{array}\right) \cdot\left(\begin{array}{l}v_{1} \\ v_{2}\end{array}\right)$

The resulting system governed by the above state and input transformation is given by:

$$
\begin{aligned}
& \dot{\mathrm{z}}_{1}=\mathrm{f}_{1}(\mathrm{z})+\mathrm{g}_{1}(\mathrm{z}) \cdot \mathrm{u}_{1}=-\frac{2}{\mathrm{~T}_{\mathrm{r}}} \mathrm{z}_{1}+\frac{2 \mathrm{~L}_{\mathrm{m}}}{\mathrm{T}_{\mathrm{r}}} \mathrm{z}_{1} \cdot \mathrm{v}_{1} \\
& \dot{\mathrm{z}}_{2}=\mathrm{f}_{2}(\mathrm{z})+\mathrm{g}_{2}(\mathrm{z}) \cdot \mathrm{u}_{2}=-\frac{\mathrm{T}_{\mathrm{L}}}{\mathrm{J}}+\frac{\mathrm{pL} \mathrm{L}_{\mathrm{m}}}{\mathrm{JL}_{\mathrm{r}}} \mathrm{z}_{1} \cdot \mathrm{v}_{2}
\end{aligned}
$$


The system is made up of two subsystems, each one is put in canonical form and dependent on one command $\mathrm{v}_{\mathrm{i}}$. The block diagram of the resulting nonlinear feedback control system (12) is depicted in Fig. 2.

The block describing the relation between $\mathrm{u}$ and $\mathrm{v}$ cannot be replaced by an approximate system, because of no uncertainty between internal and external command variables is tolerated.

Concepts of the Sliding Mode Control (SMC): The basic principle of sliding mode control consists in moving the state trajectory of the system toward a predetermined surface called sliding or switching surface and in maintaining it around this latter with an appropriate switching logic. The design of a sliding mode controller has two steps, namely, the definition of the adequate switching surface $\mathrm{S}(\cdot)$ and the development of the control law or the switching logic U.

Concerning the development of the switching logic, it is divided into two parts, the equivalent control $\mathrm{U}_{\mathrm{eq}}$ and the attractivity or reachability control $\mathrm{U}_{\mathrm{n}}$ defined as follows (Slotine and Li, 1991; Utkin, 1992):

$\mathrm{U}=\mathrm{U}_{\mathrm{eq}}+\mathrm{U}_{\mathrm{n}}$

With:

$\mathrm{U}_{\mathrm{n}}=-\mathrm{G}(\mathrm{S}(\cdot)) \cdot \operatorname{sgn}(\mathrm{S}(\cdot))$

Where:

$\mathrm{U}_{\mathrm{eq}}=$ Equivalent control

$\mathrm{U}_{\mathrm{n}}=$ Robust control

Equivalent control $\mathbf{U}_{\text {eq }}$ : The equivalent control is determined off-line with a model that represents the plant as accurately as possible. It is calculated by imposing $\dot{\mathrm{S}}(\cdot)=0$ and $\mathrm{S}(\cdot)=0$; which force the state variables to follow the sliding surfaces. If the plant is exactly identical to the model used for determining $U_{\text {eq }}$ and there are no disturbances, there would be no need to apply an additional control $U_{n}$. In this case this condition yields to:

$\frac{\partial \mathrm{S}}{\partial(\cdot)}[\mathrm{f}(\cdot)+\mathrm{g}(\cdot) \cdot \mathrm{u}]+\frac{\partial \mathrm{S}}{\partial \mathrm{t}}=0$

where, $\frac{\partial S}{\partial(\cdot)}$ the gradient of $S$ with respect to state variable. From Eq. 20 the equivalent control is given by:
$\mathrm{U}_{\mathrm{eq}}=-\left[\frac{\partial \mathrm{S}}{\partial(\cdot)} \mathrm{g}(\cdot)\right]^{-1}\left[\frac{\partial \mathrm{S}}{\partial(\cdot)} \mathrm{f}(\cdot)+\frac{\partial \mathrm{S}}{\partial \mathrm{t}}\right]$

For a stationary sliding surface $\dot{\mathrm{S}}(\cdot)=0$ thus:

$\mathrm{U}_{\mathrm{eq}}=-\left[\frac{\partial \mathrm{S}}{\partial(\cdot)} \mathrm{g}(\cdot)\right]^{-1}\left[\frac{\partial \mathrm{S}}{\partial(\cdot)} \mathrm{f}(\cdot)\right]$

$\frac{\partial \mathrm{S}}{\partial(\cdot)} \mathrm{g}(\cdot)$ is assumed to be non-singular for all state variables.

In the present work, the two equivalent controls $\mathrm{U}_{\text {eq }}$, that force the state variables to follow the sliding surfaces, of the sliding mode controllers used in the cascade structure are calculated by imposing $\dot{\mathrm{S}}_{\mathrm{i}}(\mathrm{z})=0$ and $\dot{\mathrm{S}}_{\mathrm{ij}}(\mathrm{u})=0$, where $\mathrm{i}: 1,2$ and $\mathrm{j}: 3,4$.

Robust control $\mathbf{U}_{\mathbf{n}}$ : However, in practice there are a lot of differences between the model and the actual plant. Therefore, the control component $U_{n}$ is necessary to guarantee that the state is attracted by the switching surface in satisfying the condition $\mathrm{S}(\cdot) \cdot \dot{\mathrm{S}}(\cdot)<0$ in the presence of parameter uncertainties and disturbance uncertainties (Slotine and Li, 1991; Utkin, 1992).

In a conventional variable structure control the reachability control generates a high control activity as it depends on the magnitude $\mathrm{G}(\cdot)$. The resulting relay function, obtained with a constant $\mathrm{G}(\cdot)$ is very harmful to the actuators and may excite the unmodeled dynamics of the system. This is known as a chattering phenomenon. The main cause of the chattering and the large control energy is the use of a control law that depends only on the known upper bounds of uncertainties and disturbances. Ideally, to reach the sliding surface, the chattering phenomenon should be eliminated. However, in practice, chattering can only be reduced.

During the last years, the reduction of chattering became a focus of many researches (Barazane et al., 2007; 2009) Park and Kim, 1991; Slotine and Li, 1991; Utkin, 1992). Among these, the first approach to reduce chattering was to introduce a boundary layer around the sliding surface and to use smooth functions to replace the discontinuous part of the control action. In this work the following function, which gives higher performances as it uses an exponential function for smoothing, is proposed (Fig. 3) (Barazane et al., 2009):

$\mathrm{G}(\mathrm{S})= \begin{cases}\mathrm{k}-(\mathrm{k}-\mathrm{k}) \exp \left(-\frac{|\mathrm{S}(\cdot)|-\varepsilon}{2}\right) ; & |\mathrm{S}(\cdot)|\rangle \varepsilon \\ \frac{\mathrm{k}}{\varepsilon} ; & |\mathrm{S}(\cdot)| \leq \varepsilon\end{cases}$ 


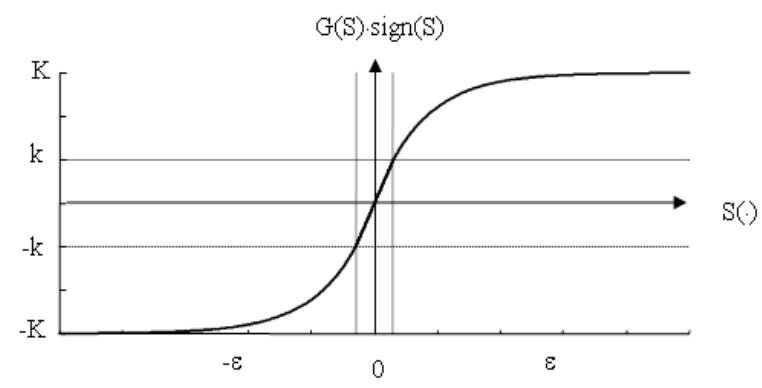

Fig. 3: A smooth piecewise approximation.

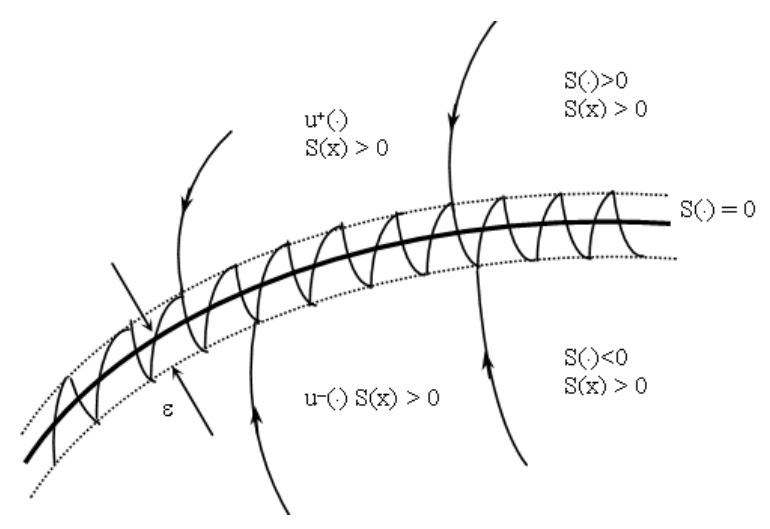

Fig. 4: Illustration of the tracking around the predefined sliding surface

The constant $\mathrm{K}$ is linked to the speed of convergence towards the sliding surface of the process (the reaching mode). Compromise must be made when choosing this constant, since if $\mathrm{K}$ is very small the time response is important, whereas when $\mathrm{K}$ is too big the chattering phenomenon appears.

$k$ is the minimal value of $G(S)$, necessary to compensate uncertainties and disturbances to guarantee convergence to the boundary layer.

The value of $\varepsilon$ is important as it affects simultaneously the switching frequency and the tracking of the sliding surface as shown in Fig. 4. Thus, $\varepsilon$ is chosen with great care in order to obtain the best possible and practical results.

\section{Application of the sliding mode control in the proposed system:}

Conception of the sliding mode controllers: In this contribution, the sliding mode control scheme is illustrated in Fig. 5. Using Park transformation, the reference voltages in the $(\mathrm{a}, \mathrm{b}, \mathrm{c})$ co-ordinates are given by:

$$
\left[\begin{array}{c}
\mathrm{V}_{\mathrm{as}} \\
\mathrm{V}_{\mathrm{bs}} \\
\mathrm{V}_{\mathrm{cs}}
\end{array}\right]=\frac{2}{3}\left[\begin{array}{cc}
1 & 0 \\
-1 / 2 & \sqrt{3} / 2 \\
-1 / 2 & -\sqrt{3} / 2
\end{array}\right] \cdot\left[\begin{array}{c}
\mathrm{V}_{\mathrm{\alpha s}} \\
\mathrm{V}_{\beta s}
\end{array}\right]
$$

Design of the switching surfaces: In this study, two sliding surfaces are taken as (Barazane et al., 2009; 2004; 2007):

$\mathrm{S}_{1}\left(\mathrm{z}_{1}\right)=\mathrm{e}_{1}\left(\mathrm{z}_{1}\right)=\Phi_{\text {rref }}^{2}-\Phi_{\mathrm{r}}^{2}=\mathrm{z}_{1 \mathrm{ref}}-\mathrm{z}_{1}$

$\mathrm{S}_{2}\left(\mathrm{z}_{2}\right)=\mathrm{e}_{2}\left(\mathrm{z}_{2}\right)=\Omega_{\text {ref }}-\Omega=\mathrm{z}_{2 \mathrm{ref}}-\mathrm{z}_{2}$

with $\Phi_{\text {rref }}$ and $\Omega_{\text {ref, }}$, being respectively, the reference values of the flux and the speed.

Development of the control laws: By using (20) and (21), the two regulators' control laws, for the flux and the speed, are given by the following equations (Barazane et al., 2009; 2005):

- For the flux regulator:

$$
\mathrm{v}_{1}=\left(\frac{-\lambda_{1} \dot{\mathrm{Z}}_{\mathrm{lref}}+\lambda_{1} \cdot \frac{2}{\mathrm{~T}_{\mathrm{r}}} \mathrm{Z}_{1}}{\frac{2 \mathrm{~L}_{\mathrm{m}}}{\mathrm{T}_{\mathrm{r}}} \mathrm{Z}_{1}}\right)+\left(\frac{-1}{\frac{2 \mathrm{~L}_{\mathrm{m}}}{\mathrm{T}_{\mathrm{r}}} \mathrm{Z}_{1}}\right) \cdot \dot{\mathrm{S}}_{\mathrm{ld}}
$$

- For the speed regulator:

$$
\mathrm{v}_{2}=\left(\frac{-\lambda_{2} \dot{\mathrm{Z}}_{2 \mathrm{ref}}+\lambda_{2} \cdot \frac{\mathrm{C}_{\mathrm{r}}}{\mathrm{J}}}{\frac{\mathrm{pL}_{\mathrm{m}}}{\mathrm{JL}_{\mathrm{r}}} \mathrm{Z}_{1}}\right)+\left(\frac{-1}{\frac{\mathrm{pL} \mathrm{m}_{\mathrm{m}}}{\mathrm{JL}_{\mathrm{r}}} \mathrm{Z}_{1}}\right) \cdot \dot{\mathrm{S}}_{2 \mathrm{~d}}
$$

They can be rewritten as:

$\mathrm{v}_{1}=\mathrm{v}_{\mathrm{leq}}\left(\mathrm{z}_{1}\right)+\mathrm{b}_{1}\left(\mathrm{z}_{1}\right) \cdot \dot{\mathrm{S}}_{\mathrm{ld}}$

$\mathrm{v}_{2}=\mathrm{v}_{2 \mathrm{eq}}\left(\mathrm{z}_{1}\right)+\mathrm{b}_{2}\left(\mathrm{z}_{1}\right) \cdot \dot{\mathrm{S}}_{2 \mathrm{~d}}$

With:

$\dot{\mathrm{S}}_{1 \mathrm{~d}}\left(\mathrm{~S}_{1}\right)=\mathrm{M}_{1}\left(\mathrm{~S}_{1}\right) \cdot \operatorname{sgn}\left(\mathrm{S}_{1}\right)$

$\dot{\mathrm{S}}_{2 \mathrm{~d}}\left(\mathrm{~S}_{2}\right)=\mathrm{M}_{2}\left(\mathrm{~S}_{2}\right) \cdot \operatorname{sgn}\left(\mathrm{S}_{2}\right)$

The gains $\mathrm{K}_{1}, \mathrm{~K}_{2}, \mathrm{k}_{1}$ and $\mathrm{k}_{2}$ should first be taken positive and then adjusted to the appropriate values which correspond to the highest performances of the system. 


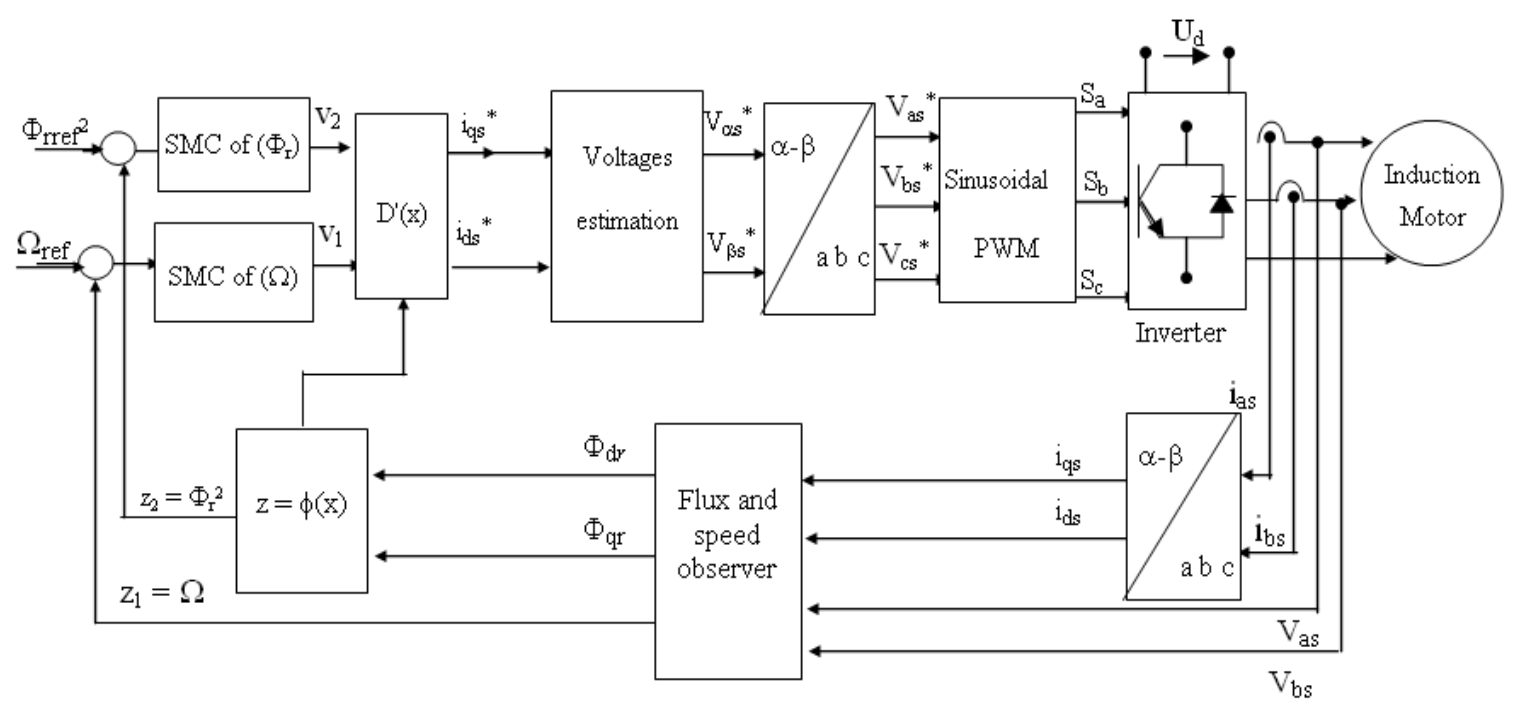

Fig. 5: Block diagram of the cascade sliding mode control of induction motor

\section{MATERIALS AND METHODS}

It is important to precise that in this study the material which is used is the Matlab simulink and its different toolbox such as the conception of our ANFIS system by using ANFIS toolbox. This is also done by in the vision of implementing in the future such a system by using D-space.

Validation of the cascade sliding mode controller: The first test concerns a no-load starting of the motor with a reference speed $\Omega_{\text {ref }}=100 \mathrm{rd} \mathrm{sec}^{-1}$. A load torque $\left(T_{L}=10 \mathrm{Nm}\right)$ is applied then between $\mathrm{t}=0.8 \mathrm{sec}$ and $\mathrm{t}=1.5 \mathrm{sec}$.

The test results obtained are shown in Fig. 6.

The waveforms depicted in the Fig. 6 show that the ideal variable decoupling is established, despite the load variations. Owing to the constant flux control, a quick speed response is thus obtained. Besides, this speed response is very close to the desired reference. It is clearly shown that during a load torque perturbation, the actual rotor speed tracks the desired speed after a small transient state. The step changes in the load torque and the speed response cause step changes in the torque response without any effects on the rotor flux components responses $\left(\Phi_{\alpha \mathrm{r}}, \Phi_{\beta \mathrm{r}}\right)$, which are maintained constants, due to the decoupled control system between speed and rotor flux.

A cascade structure with sliding mode control has been simulated using a squirrel-cage induction motor of $1.5 \mathrm{Kw}, 220 \mathrm{~V}, 2$ pairs of poles, $1420 \mathrm{tr} / \mathrm{min}, 50 \mathrm{~Hz}$, $\mathrm{R}_{\mathrm{s}}=4.85 \Omega, \mathrm{R}_{\mathrm{r}}=3.805 \Omega, \mathrm{L}_{\mathrm{s}}=0.274 \mathrm{H}, \quad \mathrm{L}_{\mathrm{r}}=0.274 \mathrm{H}$, $\mathrm{M}=0.258 \mathrm{H}, \mathrm{J}=0.031 \mathrm{Kg} . \mathrm{m}, \mathrm{f}=0.00114 \mathrm{Nms}$.

On the other hand, the speed regulation is obtained using such a controller in spite of the presence of severe disturbances such as load torque step changing. Concerning the chattering phenomenon, this latter appears in the torque response due to the discontinuous characteristic of the controller. It could not be eliminated with this technique of control.

Improvement of the control system by using Adaptive Neuro-Fuzzy Inference System (ANFIS): Design of the speed Adaptive neuro-fuzzy inference: In this study, only the speed fuzzy sliding mode controller will be replaced by an adaptive neuro- fuzzy inference system because the hybrid technique ensure the decoupling between the torque and rotor flux and also the chattering appear on the torque response especially and must be reduced. So, it is realized by an appropriate combination of neural and fuzzy systems in order to try to reduce or eliminate the chattering. This hybrid combination enables to utilize both the verbal and the numeric power of intelligent systems (Efe and Kaynak, 1999; Jang et al., 1997). Note that the hybrid structure control process independently from the ANFIS controller or any other type of regulator imposed that in order to have the best decoupling the velocity and the other parameter of the motor must be estimated correctly. We supposed here that the velocity is not changed during the process (the variation of this latter and its impact on the response of the electromagnetic torque is presented (Barazane et al., 2009)). 

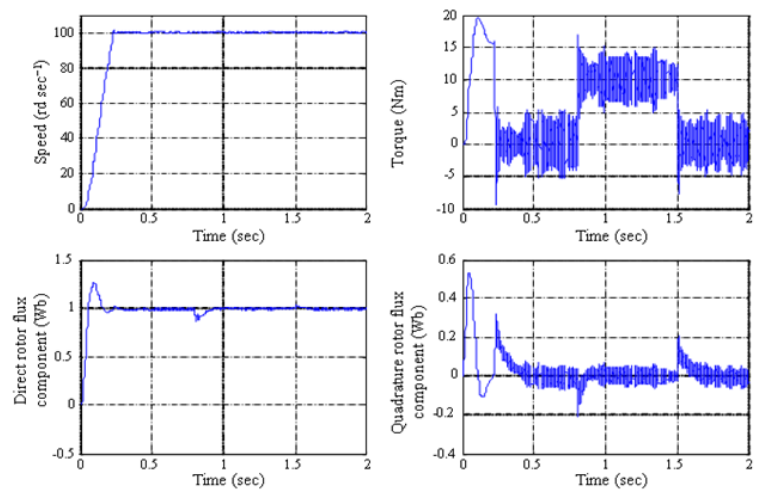

Fig. 6: Simulation results for the sliding mode control

As it is known from the theory of fuzzy systems, different fuzzification and defuzzification strategies with rule base structures can result in various solutions to a given task. This study considers the ANFIS structure with first Sugeno Model containing nine rules. Gaussian membership functions with product inference rule are used at the fuzzyfication level. Fuzzyfier outputs the firing strengths for each rule. The vector of the firing strengths is normalized and the resulting vector is defuzzyfied by utilizing the first order Sugeno model.

Note that our ANFIS controller has two inputs chosen as the speed estimated at times $(\mathrm{t})$ and $(\mathrm{t}-1)$ respectively and one output which correspond to the control law $\mathrm{v}_{1}$ given in Fig. 5.

Validation of the speed regulation by using adaptive neuro-fuzzy inference controller: Initially, before the introduction of the speed adaptive neuro-fuzzy controller in the control scheme, we must proceed to its training. This process is done off-line by presenting to the controller the pattern (input/ output data) obtained during the simulation of the previous system. Note that only data obtained in transient state was used in this training process in order to give more capabilities to the ANFIS because during this phase of the process many different points are given which leads to a good generalization of our controller to unknown cases. Also we considered the sliding mode obtained data because in this case the system is more performed and the robustness ensured. After this step and in order to verify if the adopted speed adaptive neuro-fuzzy controller would be capable of driving the plant in all the operating range and without instability, we insert it in the control scheme to replace the speed sliding mode controller and validate its performances by doing the same test simulation such as those which are done previously in the sliding mode control (Fig. 7).
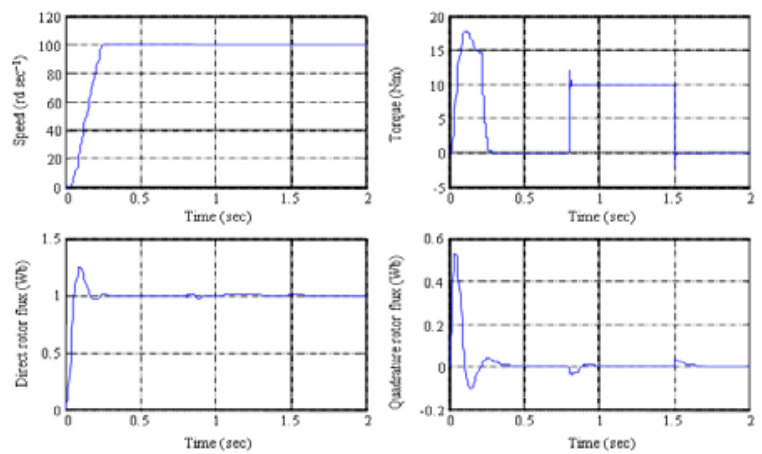

Fig. 7: Simulation results for the neuro-fuzzy control
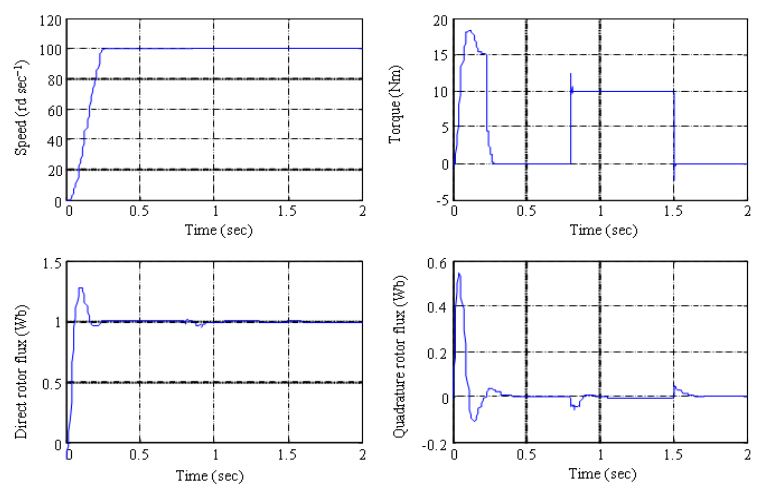

Fig. 8: Simulation results for the neuro-fuzzy control taking into account the variation of $50 \% \mathrm{R}_{\mathrm{r}}$

On the other hand and as the coefficients in (18) are all dependent on the motor parameters. These parameters may vary during on-line operation due to temperature or saturation effects. So, it is important to investigate the sensitivity of the complete system to parameters' changes. One of the most significant parameter changes in the motor is the rotor resistance $R_{r}$. A simulation taking into account the variation of $50 \%$ rise of $\mathrm{R}_{\mathrm{r}}$ relative to the identified model parameter was carried out (Fig. 8).

\section{RESULTS AND DISCUSSION}

The waveforms depicted in Fig. 7 show that the responses obtained with the ANFIS controller are highly similar to those illustrated in Fig. 5 and 6 respectively. In fact, the decoupling between the speed and the direct rotor flux component is maintained by the use of the feedback linearization control method such as the robustness towards the rotor resistance variation $(50 \%$ Rr) which is clearly shown by Fig. 8. Furthermore, we can also notice that the chattering is approximately inexistent by the use of such intelligent system which 
represents the most important objectives required by the authors. In fact, as a conclusion, we can say that our objectives (decoupling, robustness and a significant reduction of the chattering phenomenon) are attempt and that the speed adaptive neuro-fuzzy controller proves that it has got great potentials to improve the responses of the system. In the future we intend to implement our proposed system by using D-space in order to validate the obtained simulation's results by experimentation. However and as a recommendation for the future work we will try to Gaussian membership function in the conception of the ANFIS controllers as basis in order to ameliorate our responses.

\section{CONCLUSION}

The sliding mode control of the field oriented induction motor was proposed. To show the effectiveness and performances of the developed control scheme, simulation study was carried out. good results were obtained despite the simplicity of the chosen sliding surfaces. The robustness and the tracking qualities of the proposed control system using sliding mode controllers appear clearly.

Furthermore, in order to reduce the chattering, due to the discontinuous nature of the controller, fuzzy logic controllers were added to the sliding mode controllers. These gave good results as well and simplicity with regards to the adjustment of parameters and the implementation comparing to the use of smoothing functions.

On the other hand, the introduction of the speed neuro-fuzzy controller gives the most important reduction of the chattering. So, the objectives of this contribution were attempt with success.

\section{REFERENCES}

Barazane, L., Y. Sellami, R. Ouiguini, M. Larbes and M.S. Boucherit et al., 2004. A new fuzzy model representation of a cascade structure of induction motor drives. Electromotion, 11: 45-55.

Barazane, L., R. Ouiguini and M.S. Boucherit, 2005. A novel fuzzy modeling representation of induction motor. Proceeding of the International Symposium on Information and Communication Technologies, (ICT'05), Casablanca, Morocco, pp: 107-112.

Barazane, L., M. Laribi and M. Jumah, 2007. Introduction of fuzzy sliding mode technique in the feed back-linearization control of induction motor. Proceeding of the 1st International Conference on Digital Communication and Computer Applications, Mar. 19-22, Irbid, Jordan, pp: 19-25.
Barazane, L., M.M. Krishan and A. Khwaldeh, 2009. Robust neural networks for hybrid control of asynchronuous motor drives. Proceedings of the 3rd International Conference on Electrical and Electronics Engineering, May 19-21, IEEE Xplore Press, Algiers, Algiers, pp: 31-37.

Efe, M.O. and O. Kaynak, 1999. A comparative study of neural network structures in identification of nonlinear systems. Mechatronics, 9: 287-300. DOI: 10.1016/S0957-4158(98)00047-6

Ghalia, M.B. and A.T. Alouani, 1995. Sliding mode control synthesis using fuzzy logic. Proceeding of the American Control Conference, June 21-23, IEEE Xplore Press, Seattle, Washington, USA., pp: $1528-1532$.

http://ieeexplore.ieee.org/xpl/freeabs_all.jsp?arnum ber $=521007$

Hunt, K.J. and D. Sbarbaro, 1991. Neural networks for nonlinear internal model control. IEEE Proc. D Control Theor. Appli., 138: 431-438. http://ieeexplore.ieee.org/xpl/freeabs_all.jsp?arnum ber $=92956$

Isidori, A., 1999. Nonlinear Control Systems: Communications and Control Engineering. 3rd Edn., Springer, Berlin, ISBN: 10: 1852331887, pp: 293.

Jang, J.S.R., 1993. ANFIS: Adaptive-network-based fuzzy inference system. Proc. IEEE Trans. Syst. Man Cybernet., 23: 665-685. DOI: 10.1109/21.256541

Jang, J.S.R., C.T. Sun and E. Mizutani, 1997. NeuroFuzzy and Soft Computing: A Computational Approach to Learning and Machine Intelligence. US Edn., Prentice Hall, USA., ISBN: 10: 0132610663, pp: 614.

Kosko, B., 1992. Neural networks and fuzzy systems: A Dynamical Systems Approach to Machine Intelligence. Prentice-Hall Inc., Upper Saddle River, New Jersey, USA., ISBN: 0-13-612334-1, pp: 449.

Li, H.X., H.B. Gatland and A.W. Green, 1997. Fuzzy variable structure control. Proc. IEEE Trans. Syst. Man. Cybernet. $\quad 27$ 306-312. http://www.ncbi.nlm.nih.gov/pubmed/18255871

Narendra, K.S. and K. Parthasarathy, 1990. Identification and control of dynamical systems using neural networks. Proc. IEEE Trans. Neural Networks, $\quad 1$ : 4-27. http://www.ncbi.nlm.nih.gov/pubmed/18282820

Park, M.H. and K.S. Kim, 1991. Chattering reduction in the position control of induction motor using the sliding mode. Proc. IEEE Trans. Power Elect., 6: 317-325. DOI: 10.1109/63.85898 
Am. J. Applied Sci., 7 (1): 110-119, 2010

Slotine, J.J.E. and W. Li, 1991. Applied Nonlinear Control. 1st Edn., Prentice Hall, Englewood Cliffs, NJ., ISBN: 0130408905, pp: 459.
Utkin, V.I., 1992. Sliding Mode Control and Optimization. Springer-Verlag, Berlin, Heidelberg, New York, ISBN: 0-129-88562-15. 